\title{
Konsep Pendidikan Tasawuf Amali menurut Syaikh Utsman ibn Hasan ibn Ahmad Syakir Al-Khaubawi dalam Kitab Durrah An-Nasihin dan Implementasinya dalam Pembelajaran PAI
}

\author{
Rifyal Luthfi MR, Gunawan Anjar \\ Program Studi Pendidikan Agama Islam (STAI) Tasikmalaya \\ Jl. Noenoeng Tisna Saputera No 16 Kota Tasikmalaya \\ Email : zime1984@gmail.com
}

\begin{abstract}
The concept of Sufi mysticism education is in accordance with the 21st century because the present condition of mankind is in the era of materialism and self-control over Islamic guidance and norms as a result of the effects of globalization and modernization. From the above reasons, the author is interested in analyzing the book of Durrah AnNasihin written by Shaykh Uthman ibn Hasan ibn Ahmad Syakir Al-Khaubawi to be used as a reference in finding the concept of Sufi Sufi education also this book has its uniqueness and ideas which are read by pesantren (santri) as a basis for thinking, acting, behaving and saying. This study aims to explain the concept of Amali mysticism education according to the book of Durrah An-nasihin and its implementation in the learning of Islamic Education. This research is a qualitative study with library research. The primary data source used is the book of Durrah An-Nasihin and the secondary data are the Al-Qur'an, Hadith, articles and other scientific books. The data collection is carried out by documenting the collection of one's data in the form of writing, drawing or work. The results showed that the concept of Amali Sufism education according to the book of Durrah An-Nasihin contains four main things, namely wara ', spending wealth in the way of Allah, following the sunnah of the Prophet saw and making friends with the poor and poor. The implementation of the concept of Sufism in Amy is in the eyes of the Islamic Education Aqeedah moral lessons class XI even semester.
\end{abstract}

Keywords: Amali Sufism. book of Durrah An-Nasihin, PAI Learning

Abstrak

Konsep pendidikan tasawuf amali yang sesuai dengan abad 21 karena kondisi sekarang manusia berada pada zaman materialisme dan mengendalikan diri diatas tuntunan dan norma islami sebagai akibat dari akibat pengaruh arus globalisasi dan modernisasi. Dari alasan diatas, penulis tertarik untuk menganalisis kitab Durrah An-Nasihin yang dikarang oleh syaikh Utsman ibn Hasan ibn Ahmad Syakir Al-Khaubawi untuk dijadikan rujukan dalam menemukan konsep pendidikan tasawuf amali juga kitab ini memiliki keunikan dan gagasan yang menjadi bacaan kaum pesantren (santri) sebagai landasan berfikir, bertindak, berperilaku dan berucap. Penelitian ini bertujuan untuk menjelaskan konsep pendidikan tasawuf amali menurut kitab Durrah An-nasihin dan implementasinya dalam pembelajaran PAI.penelitian ini merupakan penelitian kualitatif dengan kajian pustaka (library research). Sumber data primer yang digunakan ialah kitab Durrah An-Nasihin dan data sekundernya adalah Al-Qur'an, Hadits, artikel dan buku ilmu pengetahuan lainnya.adapun pengumpulan data dilakukan ialah dokumentasi yakni pengumpulan data seseorang baik berupa tulisan, gambar atau karya. Hasil penelitian menunjukan bahwa konsep pendidikan tasawuf amali menurut kitab Durrah An-nasihin mengandung empat hal pokok, yaitu wara', menafkahkan harta di jalan Allah, mengikuti sunnah nabi saw dan berteman dengan fakir dan miskin.Implementasi konsep tasawuf amali dalam pembelajaran PAI terdapat pada mata pelajaran aqidah akhlak kelas XI semester genap.

Kata Kunci: Tasawuf Amali. kitab Durrah An-Nasihin, Pembelajaran PAI

\section{PENDAHULUAN}

Dewasa ini manusia hidup pada abad 21 yang merupakan masa kemajuan peradaban manusia. Modernisasi yang kemudian diikuti globalisasi yang tidak terbendung memunculkan kesulitankesulitan baru dalam kehidupan. Globalisasi tidak hanya mendominasi perekonomian tetapi juga telah mencengkram dan merubah kehidupan sosial dan budaya serta lingkungan hidup. Masyarakat telah terperangkap dalam pola pikir rasional dan mencampakkan dimensi batin. Mereka hanya berfikir kehidupan duniawi semata tanpa menghiraukan kehidupan $u k h r a w i$.

Cara memandang, sikap dan tindakan seperti itu bertentangan dengan tasawuf yang mendorong manusia untuk hidup prihatin dan sederhana, menjauhi kehidupan dunia yang gemerlap. Pada dasarnya ajaran tasawuf adalah pengendalian hawa nafsu, menghapus keserakahan, mengendalikan kecenderungan yang bersifat badani, melepaskan diri dari ketakutan terhadap hari esok. Hakikat tasawuf adalah perpindahan sikap mental dan keadaan jiwa dari suatu keadaan pada keadaan lain yang lebih baik, lebih 
tinggi dan lebih sempurna. (Anwar, 2010, hal. 149). Tasawuf bukan lagi menjadi tempat pelarian sementara manusia, namun merupakan suatu keniscayaan yang sungguh-sungguh sehingga tasawuf akan eksis ditengah-tengah percaturan dunia modern (Syukur, Menggugat Tasawuf, 1999, hal. 147).

Zaman modern adalah zaman ketika orang berpendapat bahwa kebutuhan pokok hidup manusia (sandang, pangan dan papan) harus diatur seserasi mungkin sehingga bisa ditingkatkan sejauh mungkin (Rachman, 2012, hal. 3312). Orang-orang modern disibukan dengan berbagai bentuk kemajuan dan perkembangan dimensi material namun melupakan dimensi spiritual. Orang-orang modern mengalami exixtensial vacuum (kekosongan eksistensi) yang ditandai dengan kebosenan dan ketidakjelasan hidup (Rakhmat, 1997, hal. 477). Tiba-tiba mereka memasuki satu dunia yang luas, uang yang banyak, namun tidak tahu bagaimana menghidupi kehidupan. Masyarakat mengalami kegersangan spritual yaitu sebuah perasaan hampa yang menyelubungi jiwa walaupun secara material mempunyai materi yang berlimpah. Mereka juga mengalami dekadensi moral yang dapat dilihat dengan berbagai bentuk kejahatan yang selalu hadir dalam kehidupan sehari-hari. Maraknya pencurian, seks bebas, pembunuhan dan terkikisnya nilai-nilai etis religius merupakan sejumlah fakta nyata tentang dekadensi moral (Muhayya, 2001, hal. 5). Selain itu perkembangan ilmu pengetahuan lepas dari pengaruh agama dan menolak realitas abstrak yang bisa didekati dengan metode intuitif (Wiwoho, 2016, hal. 297). Dunia kontemporer mengizinkan merajalelanya budaya permisif yang terlepas dari norma religius dan norma etis masyarakat (Zaprulkhan, 2016, hal. 289). Sebagai hasilnya perbuatan buruk yang menjadi keinginan serta didorong oleh hawa nafsu menjadi pilihan hidup manusia yang sah bukan penyakit mental yang perlu diterapi.

Berdasarkan kenyataan tersebut, ilmu tasawuf menjadi sangat penting dan sangat dibutuhkan karena ia dapat membebaskan seseorang dari pengaruh kehidupan dunia sehingga dia punya akhlak yang mulia dan dekat dengan Allah swt (Anwar M. S., 2005, hal. 154). Tasawuf berurusan dimensi batin manusia yang berperan membersihkan hati sanubari manusia(Nata, Akhlak Tasawuf, cet. 4, 2002, hal. 178). Oleh karena itu, tasawuf merupakan solusi yang tepat untuk menangani problematika masyarakat kontemporer. Ilmu tasawuf sebagai anggur murni spiritual yang sudah ada sejak zaman Nabi Adam a.s, hingga zaman kontemporer hari ini yang akan selalu dibutuhkan untuk memenuhi kedahagaan ontologis umat manusia sampai hari kiamat kelak (Bagoesoka, 2003, hal. 194-195). Tasawuf bukan hanya untuk manusia klasik namun untuk manusia yang bisa menyesuaikan diri dimana saja dan kapan saja karena kualitas tasawuf manusia yang sebenarnya dapat diukur dari kemampuan manusia mempertahankan sifat insan kamil dalam menghadapi berbagai zaman.

Tasawuf adalah pengetahuan yang dipraktekkan bukan sekedar ilmu yang dibicarakan. Praktek ialah membiasakan diri dengan ajaran/kebiasan tertentu secara konsisten. Sabar, tawakal, prihatin, ikhlas, mengekang diri, wara', zuhud, khusyu adalah contoh amaliah tasawuf. Tasawuf amali lebih menekankan pada nilai amaliahnya dibandingkan teori.Tasawuf amali ialah suatu ajaran dalam tasawuf yang lebih menekankan amalan-amalan rohaniah dibandingkan teori(Solikhin, 2004, hal. 13). Tasawuf amali lebih menekankan pembinaan moral dalam upaya mendekatkan diri kepada Tuhan. Untuk mencapai hubungan yang dekat dengan Tuhan, seseorang harus mentaati dan melaksanakan syariat atau ketentuan agama, menghapuskan segala sifat yang tercela, melintasi semua hambatan itu dan menghadap total dari segenap esensi diri hanya kepada Allah swt dengan berbagai wirid dan amaliahamaliah lainnya. Dinamakan tasawuf amali karena sisi amal di dalamnya lebih dominan dari sisi teori. Tasawuf amali tidak hanya sekedar mengetahui tentang teori, akan tetapi langsung dipraktikan dalam ibadahnya sehingga dalam bertasawuf seseorang lebih bisa merasakan tujuan tasawuf tersebut yaitu kedekatan seorang hamba kepada Yang Maha Kuasa.

Konsep pendidikan tasawuf amali sangat dibutuhkan oleh setiap individu maupun masyarakat karena jika ditelaah secara mendalam tasawuf amali memiliki aspek-aspek strategis yang potensial dalam segala sendi kehidupan manusia, tetapi esensi tersebut akan sia-sia apabila umat Islam tidak mampu memanfaatkan konsep pendidikan tasawuf amali tersebut dengan sebaik-baiknya. Sebagaimana dampak negatifnya ketika ia diremehkan akan menyebar pada indivdu dan masyarakat.

Untuk merespon tuntutan agenda konseptual pendidikan tasawuf amali, salah satunya adalah melalui orientasi pengkajian ulang terhadap khazanah pemikiran Islam klasik. Kitab Durrah An-Nasihin karya Syaikh Utsman ibn Hasan ibn Ahmad Syakir Al- Khaubawi nampaknya patut untuk menjadi objek kajian yang dimaksud karena pemikiran dan gagasan kitab tersebut menjadi kajian wajib kaum pesantren sebagai landasan berfikir, berperilaku dan beribadah sehingga tidak ada salahnya kalau 
kemudian gagasan tersebut dibawa ke dunia yang lebih luas dan kondusif untuk menjadi bagian dari diskursus keilmuan akademik.

Dalam kitab tersebut Syaikh Utsman menjelaskan bahwa tanda kebahagiaan ada sebelas, salah satunya ialah zuhud terhadap dunia dan cinta kepada akhirat serta senantiasa ingin beribadah dan bertaqarub kepada Allah swt(Tsaqief, 2015, hal. 486). Kitab Durrah An-Nasihin karya Syaikh Utsman ibn Hasan ibn Ahmad Syakir Al- Khaubawi disusun berdasarkan motivasi untuk para pecinta nasehat. Kitab ini memberikan penjelasan dalam bentuk keutamaan-keutamaan dari setiap ibadah disertai dengan berbagai kisah dan hikayat yang diambil dari beberapa kitab lainnya. Oleh sebab itu, kitab Durrah An-Nasihin ini menyodorkan kepada semua umat manusia yang beriman bagaimana seharusnya berfikir, berucap, bertindak dan beribadah agar menjadi hamba Allah swt yang senantiasa taqarrub dengan-Nya, menemukan ketenangan batiniah/spiritual serta memperoleh kebahagiaan hidup dunia dan akhirat.

\section{KAJIAN PUSTAKA}

Para ahli merumuskan tasawuf dalam rumusan yang berbeda-beda akibat sudut pandang dan titik tekan yang berbeda namun kata shuf yang berarti bulu wol merupakan yang paling banyak diterima sebagai akar etimologi tasawuf dan sufi (Syaifuddin, 2013, hal. 18). Secara istilah tasawuf ialah suatu ilmu yang tumbuh pada abad ke-2 Hijriah, berasal dari kelompok orang-orang yang mengutamakan kesucian diri dengan menetapkan hati dan raga untuk beribadah dan menghubungkan diri kepada Allah $s w t$, menghindarkan segala kemewahan dunia dengan berusaha meningkatkan kehidupan rohani melalui thariqat, memperbanyak menyebut dan berdzikir kepada Allah serta bertaubat kepada-Nya agar kemudian menjadi manusia yang sempurna (insan kamil) (Gayo, 2014, hal. 450). Adapun tasawuf amali memiliki arti suatu ajaran dalam tasawuf yang lebih menekankan amalan-amalan rohaniah dibandingkan teori. Tujuannya yaitu mendekatkan diri kepada Allah swt dengan menghapuskan segala sifat yang tercela serta menghadap sepenuhnya kepada Allah swt dengan berbagai amaliah atauriyadhahyang dilakukan seperti memperbanyak wirid serta amaliah-amaliah lainnya (Solikhin, 2004, hal. 13).

\section{METODE PENELITIAN}

Pendekatan yang digunakan dalam penelitian ini adalah pendekatan kualitatif dengan metode Kepustakaan atau studi studi literature (library research). Adapun teknik pengumpulan data menggunakan teknik pengumpulandokumen atau dokumentasi. Penelitian ini menggunakan analisis isi (content analisys)

\section{HASIL DAN PEMBAHASAN}

1. Bibliografi Kitab Durrah An-Nasihin

Kitab Durrah An-Nasihin karya Syaikh Utsman ibn Hasan ibn Ahmad Syakir Al-Khaubawi adalah kitab yang menjelaskan tentang nasehat-nasehat, peringatan, hikayat dan penjelasan hukum. Menurut penelitian Martin van Bruinessen dan penelitian Masdar F. Mas`udi kitab Durrah An-Nasihin senantiasa dijadikan rujukan di masjid-masjid, musholla, sekolah dan terutama pesantren. Menurut Lutfi, sudah ada tujuh versi terjemahan kitab Durrah An-Nasihin berbahasa Indonesia dengan penerjemah dan penerbit yang berbeda-beda. Bahkan, Kitab DurrahAn-Nasihin begitu populer di negara lain seperti Malaysia, India, dan Turki.(el-Bimawy, 2014, hal. 2).

Salah satu ahli hadits yang meneliti hadits dalam kitab Durrah An-Nasihin adalah Lutfi Fathullah menyatakan bahwa secara keseluruhan ia menemukan sebanyak 251 hadis palsu (30\%). Sementara yang lemah 180 hadis $(21,5 \%)$, amat lemah 48 hadis $(5,7 \%)$ dan belum dapat dipastikan sebanyak 56 hadis $(6,7 \%)$. Lutfi berkesimpulan seperti itu karena dua alasan.Pertama, segi kredibilitas penulisnya, keahlian Al-Khubawi dalam ilmu-ilmu keislaman, khususnya tafsir-hadis, masih diperdebatkan. Ismail Basya, misalnya, penulis biografi Al-Khubawi, tak pernah memujinya dengan sebutan Al-`Allamahatau Al-Imam. Sementara Umar Ridha Kahhalah memuji Al-Khubawi dengan gelar wa izh (pemberi nasihat), mufassir (ahli tafsir), dan muhaddits (ahli hadis). Kedua, Karena Al-Khubawi bukan muhaddits, wajar jika kandungan kitab Durrah An-Nasihin lemah secara metodologi ilmu hadis.(AlManhaj, 2006, hal. 1). 
Sedangkan cerita-cerita yang tidak pernah terlepas dari tiap pemaparan bab-bab yang ada dalam kitabnya, pastinya memiliki tujuan sebagai media penarik para pendengar dalam rangka menumbuhkan semangat dalam menjalanan ibadah-ibadah yang diperitahkan dalam Islam.

Terlepas dari penilaian negatif akan kitab ini kitab ini memang dirasa pantas sebagai rujukan para dai dalam menyampaikan ceramahnya karena di dalamnya sendiri sudah persis menyertai buku pidato yang disertai dalil-dalil dalam tiap pembahasannya. Meskipun begitu tidak baik untuk menolak isi kitab ini begitu saja tetapi tidak bijak pula menerimanaya begitu saja tanpa tanpa pemikiran yang dalam. Kitab Durrah An-nashihin adalah jawaban ketika masyarakat sudah terpengaruh oleh kemewahan dunia yang membuat hati mereka lalai dan spiritual mereka gersang sehingga lupa cara beribadah dan bermunajat kepada sang pencipta.

Kitab Durrah An-Nasihin memiliki kesamaan dengan kitab Tanbih Al-Ghafilin karya Abu Laits Nashr ibn Muhamad ibn Ibrahim As-samarqandi. Kitab ini berisi nasihat dan hikayat untuk melembutkan hati dan membuat mata menjadi menangis. Sama dengan kitab Durrah An-Nasihin, kitab Tanbih Al-ghafilin juga berisi hadits dhoif dan cerita yang tidak sahih. Namun begitu, Abu Laits Assamarqandi membuat kitab ini atas dasar kewajiban orang yang dikaruniai ilmu pengetahuan untuk memberikan peringatan, hikmah, wejangan dan kabar gembira sebagai bentuk dakwah kepada semua orang. Diharapkan setelah manusia mengkaji isi kandungan kitab Tanbih Al-ghafilin manusia merasa masih sedikit amalnya sehingga menjadi pendorong untuk meningkatkan dan menyempurnakan ibadah dan amalnya.

2. Konsep pendidikan tasawuf amali yang terkandung dalam kitab Durrah An-Nasihin

Abu A'la Maududi menyebutkan bahwa apa yang berhubungan dengan jiwa disebut tasawuf. Tasawuf dalam Islam beresensi pada pada hidup dan berkembang mulai dari bentuk kezuhudan dalam bentuk tasawuf amali.Tujuannya yaitu untuk membentuk kesalehan seseorang baik kesalehan ritual maupun sosial (Mustaqim, 2007, hal. 7). Jika semua laku seseorang lahir maupun batin sampai pada purna tawajjuh-nya, maka kasih Allah akan selalu menyertainya. Allah akan menyibakkan tirai karamah (kelebihan) dan ilmu-ilmu Allah yang tersirat. Dan bila kesalehan ritual itu disertai dengan kesalehan sosial, Allah akan menuntun pendengaran dan penglihatan kekasih-Nya kepada hal-hal yang dicintai-Nya.

Tasawuf amali adalah ajaran yang dianut oleh pengikut tarekat (ashhâbut turuq) yang meliputi menjauhi sifaf-sifat tercela, mengutamakan mujâhadah, menghadap Allah dengan bersungguh-sungguh dan memutuskan hubungan dengan lainnya (Amaniyah, 2016).

Tasawuf amali lebih menekankan terhadap cara-cara mendekatkan diri kepada Allah swt, baik melalui amalan lahiriah maupun batiniah. Tujuannya mendekatkan diri kepada Allah swt dengan menghapuskan segala sifat yang tercela serta menghadap sepenuhnya kepada Allah swt dengan berbagai amaliah atauriyadhahyang dilakukan seperti memperbanyak wirid serta amaliah-amaliah lainnya (Solikhin, 2004, hal. 13).

Bentuk/praktik tasawuf amali meliputi segala aspek ajaran Islam. Dicontohkan oleh Rasulullah saw, para sahabat, tabi'in, tabi'it tabi'in, serta para ulama secara berantai hingga kini. Maka seiring perkembangan zaman praktiknya semakin banyak dan beragam.

Pada abad ke $13 \mathrm{H}$ seorang ulama yang bernama syaikh Utsman ibn Hasan ibn Ahmad Asy-Syakir Al-Khaubawi menjelaskan konsep tasawuf amali dalam salah satu kitabnya Durrah An-Nasihin. Praktik tasawuf amali yang beliau ajarkan diperuntukan untuk semua orang, tidak harus kepada orang-orang khawas (ahli ma'rifat dan zuhud) tetapi juga untuk orang-orang awam yang masih dangkal pemahamannya juga dapat diamalkan dalam keseharian manusia. Seperti wara', taubat, berdoa, shalat tahajud, berpuasa 6 hari di bulan syawal, menafkahkan harta di jalan Allah, berteman dengan fakir dan miskin serta istiqamah di jalan-Nya.

Wara' adalah sikap kehati-hatian terhadap sesuatu (Mustaqim, 2007, hal. 53). Seseorang yang bersikap wara' akan sangat berhati-hati dalam menjalani hidup. Dengan mengedepankan sikap wara' seseorang akan tehindar dari hal-hal yang syubhat dan haram sehingga hatinya relatif bersih dan akan memudahkan dia untuk sampai kepada Allah swt.

Wara' merupakan awal dari ketakwaan seseorang. Oleh karena itu menumbuhkan sifat kesehajaan, tulus ikhlas, sikap sosial yang positif dan menjauhkan dari sikap israf, egoisme, materialisme dan kesombongan.

Betapapun sikap wara' sangat dianjurkan namun demikian jangan sampai terkena ghurur (tipu daya) sikap wara' yang ekstrem. Oleh karena itu, Allah mengutus Rasulullah saw untuk menjadi uswah 
hasanah bagi umatnya. Bagaimana menjalani kehidupan dengan baik dan benar. Maka kita sebagai umatnya harus menjadikan Nabi sebagai panutan dalam beribadah, berperilaku, bersikap dan bertutur kata, mengikuti segala perintah dan meninggalkan larangannya serta melanjutkan misi dakwah nabi.

Karena manusia memiliki dua hubungan yakni kepada Allah dan kepada sesama manusia. Maka syaikh Utsman Al-Khaubawi menjelaskan keutamaan sikap dermawan dan tolong menolong serta tidak bersikap diskriminatif. Hal tersebut tercermin dalam penjelasannya mengenai keutamaan menafkahkan harta di jalan Allah serta bergaul dengan fakir dan miskin. Dan itulah inti ajaran tasawuf yakni bagaimana seseorang mampu merasakan kehadiran Tuhan (ma'rifatullah) yang tidak saja bersifat teosentris tetapi juga antroposentris.

3. Implementasi konsep pendidikan tasawuf amali yang terkandung dalam kitab Durrah An-Nasihin dalam pembelajaran PAI

3.1. Materi

Bahan ajar dan materi tasawuf khususnya tasawuf amali dapat diimplementasikan dalam pembelajaran PAI yaitu bagi peserta didik pada pada jenjang pendidikan MA mata pelajaran Aqidah Akhlak kelas XI semester genap. Hal tersebut sesuai dengan Peraturan Menteri Pendidikan dan Kebudayaan No. 21 Tahun 2016 tentang Standar Isi Pendidikan Dasar dan Menengah. Adapun gambaran untuk materi ini, peta Konsepnya sebagai berikut:

1. Pengertian, asal usul dan istilah-istilah dalam tasawuf

a. Pengertian Tasawuf

b. Asal Usul / Sejarah Tasawuf

c. Istilah-Istilah dalam Tasawuf

2. Fungsi dan peranan tasawuf dalam kehidupan modern
a. Karakteristik tasawuf
b. Pentingnya tasawuf
c. Hubungan tasawuf dengan akhlak

3. Contoh-contoh perilaku bertasawuf

a. Tokoh-tokoh dalam tasawuf

b. Maqamat-maqomat dalam tasawuf

4. Menerapkan tasawuf dalam kehidupan modern

a. Hikmah bertasawuf

b. Contoh orang-orang yang bertasawuf

c. Peran tasawuf dalam kehidupan modern

3.2. Metodologi

Metodologi pembelajaran yang dilakukan oleh pendidik disesuaikan dengan jenjang pendidikan dan materi yang diajarkan. Dalam Peraturan Menteri Pendidikan dan Kebudayaan Nomor 22 Tahun 2016 tentang Standar Proses Pendidikan Dasar dan Menengah disebutkan bahwa metodologi digunakan untuk mewujudkan suasana belajar dan proses pembelajaran agar peserta didik mencapai KD yang disesuaikan dengan karakteristik peserta didik dan KD yang akan dicapai. Dalam penyampaian materi tasawuf amali kepada peserta didik, guru dapat memilih dan menggunakan satu atau lebih metode pembelajaran. Adapun metode yang dapat digunakan oleh pendidik diantaranya:

1. Metode ceramah yaitu sebuah metode mengajar dengan menyampaikan informasi dan pengetahuan seecara lisan kepada sejumlah siswa yang pada umumnya mengikuti secara pasif

2. Metode diskusi adalah metode mengajar yang sangat erat hubungannya dengan memecahkan masalah (Problem solving)

3. Metode resitasi yaitu suatu metode dimana siswa diharuskan membuat resume dengan kalimat sendiri

4. Metode tanya jawab yaitu metode mengajar yang memungkinkan terjadinya komunikasi langsugn yang bersifat two way traffic sebab pada saat yang sama terjadi dialog antara guru dan siswa

3.3. Evaluasi

Evaluasi pembelajaran dilakukan untuk memantau dan mengevaluasi proses, kemajuan belajar, dan perbaikan hasil belajar peserta didik secara berkesinambungan sesuai dengan Peraturan Menteri Pendidikan dan Kebudayaan No. 23 Tahun 2016 tentang Standar Penilaian Pendidikan. Dalam UU No. 22 Tahun 2016 disebutkan bahwa evaluasi hasil pembelajaran dilakukan saat proses pembelajaran dan di akhir satuan pelajaran dengan menggunakan metode dan alat: tes lisan/perbuatan dan tes tulis. 
Penilaian/evaluasi peserta didik meliputi aspek kognitif (pengetahuan), afektif (sikap) dan psikomotorik (keterampilan). Hasil belajar adalah komponen yang tidak dapat dipisahkan dari pembelajaran dan digunakan sebagai tolok ukur untuk menentukan tingkat keberhasilan pembelajaran. Hasil belajar siswa yang tinggi dan rendah dipengaruhi oleh beberapa faktor, termasuk penerapan metode pembelajaran, (Suherman, Ade. ejournal.upi.edu/index.php/JPAK/article/view/15827 ) Diakses pada tanggal 27 Desember 2019, pukul 17.00 WIB.

1. Penilaian aspek sikap dilakukan melalui observasi/pengamatan dan teknik penilaian lain yang relevan, dan pelaporannya menjadi tanggungjawab wali kelas atau guru kelas

2. Penilaian aspek pengetahuan dilakukan melalui tes tertulis, tes lisan, dan penugasan sesuai dengan kompetensi yang dinilai

3. Penilaian keterampilan dilakukan melalui praktik, produk, proyek, portofolio, dan/atau teknik lain sesuai dengan kompetensi yang dinilai

\section{KESIMPULAN}

Kitab Durrah An-Nasihin merupakan karya syaikh Syaikh Utsman Al-Khaubawi berisi sekitar 75 fashl membahas nasehat, peringatan, hikayat dan penjelasan hukum. Satu sisi, kitab ini menjadi kajian populer di kalangan non akademisi dan sisi lain banyak akademisi yang mengkritik kitab ini sebagai kitab yang tak layak dijadikan rujukan karena banyak terdapat hadits palsu dan cerita yang mubham nama pelakunya; Konsep pendidikan tasawuf amali berdasarkan kitab Durrah An-nasihin secara garis besar mencakup empat pokok, yaitu wara', menafkahkan harta di jalan Allah, mengikuti sunnah Nabi saw dan bergaul dengan fakir dan miskin. Inti ajaran tasawuf amali ialah bagaimana seseorang mencapai ma'rifat tanpa mengesampingkan sikap sosial; Implementasi konsep pendidikan tasawuf amali dalam Pembelajaran PAI terbagi dalam tiga bagian yaitu materi, metodologi dan evaluasi. Sesuai Peraturan Menteri Pendidikan dan Kebudayaan No. 21, 22 dan 23 Tahun 2016 bahwasannya materi tasawuf khususnya tasawuf amali diajarkan pada peserta didik jenjang pendidikan MA kelas XI semeseter Genap mata pelajaran Aqidah Akhlak. Adapun metodologi dan evaluasi yang dilakukan oleh pendidik disesuaikan dengan bahan ajar dan materi yang disampaikan kepada peserta didik.

\section{DAFTAR PUSTAKA}

[1] Al-Ghazali. (t.thn.). Al-Munqidz min Adh-Dahal

[2] Al-Manhaj. (2006, Juli 2006). Dipetik Februari 02, 2017, dari Kajian hadits dalam Kitab Durratun Nashihin: almanhaj.or.id

[3] Amaniyah, A. (2016, Desember 23). DalamIslam. Dipetik April 13, 2017, dari Dalami Islam - Pusat Ilmu Islam Nusantara: http://www.Tasawuf Amali Pengertian dan Tokohtokohnya _ Dalamislam.com.htm

[4] Anwar, M. S. (2005). Akhlak Tasawuf : Manusia, Etika dan Hidup Makna. Bandung : Nuansa

[5] Anwar, M. S. (2005). Akhlak tasawuf : Manusia, Etika dan Makna Hidup. Bandung: Nuansa

[6] Anwar, M. S. (2009). Akhlak Tasawuf. Bandung: CV Pustaka Setia

[7] Anwar, R. (2010). Akhlak Tasawuf. Bandung : CV Pustaka Setia

[8] Bagoesoka, L. W. (2003). Ilmu Jiwa Berjumpa Tasawuf. Bandung: Mizan

[9] el-Bimawy, A. A. (2014, Juni 14). hadits Palsu dalam Kitab Durrah An-Nasihin. Dipetik Februari 2, 2017

[10] Gayo, N. M. (2014). Buku Pintar Islam. Jakarta: Ladang Pustaka dan Intimedia

[11] Gazalba, S. (1985). Ilmu Islam 2: Asas Agama Islam, cet. 2. Jakarta: PT Bulan Bintang

[12] Idris, Y. A.-Q. (2001). Islam dan Globalisasi Dunia. Jakarta: Pustaka Al-Kautsar

[13] Islam, D. R. (1994). Ensiklopedi Islam . Jakarta: PT Intermasa

[14] Lubis, S. (1997). Umat Islam dalam Globalisasi. Jakarta: Gema Insani Press

[15] Mahjuddin. (2001). Pendidikan Hati: Kajian Tasawuf Amali. Jakarta: Kalam Mulia

[16] Muhayya, A. S. (2001). Tasawuf dan Krisis. Semarang : IAIN Wali Songo Press 
[17] Mustaqim, A. (2007). Akhlaq tasawuf: Jalan Menuju RevoLusi Spiritual . Yogyakarta: Kreasi Wacana

[18] Mustofa, A. (2014). Akhlak Tasawuf. Bandung : CV Pustaka Setia

[19] Nata, A. (2002). Akhlak Tasawuf, cet. 4. Jakarta: PT Raja Grafindo Persada

[20] Qardhawi, Y. (1995). Kiat Islam Mengentaskan Kemiskinan. Jakarta: Gema Insani Press

[21] Rachman, B. M. (2012). Ensiklopedi Nurcholis Madjid Jilid 4. Jakarta: Democracy Project

[22] Rahman, F. (1995). Doktrin Ekonomi Islam. Yogyakarta: Dana Bakti Wakaf

[23] Rakhmat, M. F. (1997). Catatan Kang Jalal, Visi Media, Politik dan Pendidikan . Bandung: Rosdakarya

[24] Riyadi, S. D. (2003). Sufisme Klasik : Menelusuri Tradisi Teks Sufi. Bandung: Mimbar Pustaka

[25] Solikhin, M. (2004). Tasawuf Aktual. Semarang: Pustaka Nuun

[35] Suherman, A. (2018). Optimalisasi Penggunaan Metode Pembelajaran Learning Cycle "5E" dan Artikulasi Terhadap Peningkatan Hasil Belajar Peserta Didik ejournal.upi.edu/index.php/JPAK/article/view/15827 ) Diakses pada tanggal 27 Desember 2019, pukul 17.00 WIB.

[36] Syaifuddin, M. F. (2013). Tasawuf Untuk Kita Semua. Jakarta: Republika

[37] Syukur, A. (1999). Menggugat Tasawuf. Yogyakarta: Pustaka Pelajar

[38] Tsaqief, U. A.-K. (2015). Durrotun Nashihin . Semarang: Pustaka Nuun

[39] Wiwoho, B. (2016). Bertasawuf di Zaman Edan. Jakarta: Buku Republika

[40] Zaprulkhan. (2016). Ilmu Tasawuf : Sebuah Kajian Tematik. Jakarta: PT Raja Grafindo Persada

[41] Zuhra, A. (2015, Mei 08)., Tasawuf Amali dan Tasawuf Falsafi : http://www.Annisa Zuhra Yahya Tasawuf Akhlaki, Tasawuf Amali dan Tasawuf Falsafi.htm diunduh Desember 12/17, dari Tasawuf Akhlaki 